Discussion Paper No. 15-029

Forecaster Overconfidence and Market Survey Performance

Richard Deaves, Jin Lei, and Michael Schröder

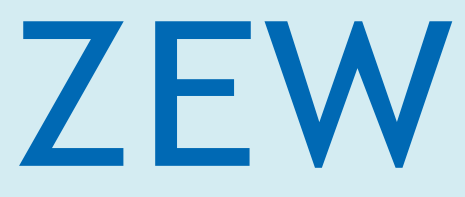

Zentrum für Europäische Wirtschaftsforschung $\mathrm{GmbH}$ Centre for European Economic Research 
Discussion Paper No. 15-029

\title{
Forecaster Overconfidence and Market Survey Performance
}

\author{
Richard Deaves, Jin Lei, \\ and Michael Schröder
}

Download this ZEW Discussion Paper from our ftp server:

http://ftp.zew.de/pub/zew-docs/dp/dp15029.pdf

Die Discussion Papers dienen einer möglichst schnellen Verbreitung von neueren Forschungsarbeiten des ZEW. Die Beiträge liegen in alleiniger Verantwortung der Autoren und stellen nicht notwendigerweise die Meinung des ZEW dar.

Discussion Papers are intended to make results of ZEW research promptly available to other economists in order to encourage discussion and suggestions for revisions. The authors are solely responsible for the contents which do not necessarily represent the opinion of the ZEW. 


\title{
Forecaster overconfidence and market survey performance
}

\author{
Richard Deaves ${ }^{a}$ \\ Jin Lei ${ }^{b}$ \\ Michael Schröderc
}

\begin{abstract}
We document using the ZEW panel of German stock market forecasters that weak forecasters tend to be overconfident in the sense that they provide extreme forecasts and their confidence intervals are less likely to contain eventual realizations. Moderate filters based on forecast accuracy over short rolling windows are somewhat successful in improving predictability. While poor performance can be due to various factors, a filter based on a prior tendency to provide extreme forecasts also improves predictability.
\end{abstract}

Keywords: Overconfidence, Forecasting Performance, Stock Market

JEL Classification: G02, G17

a McMaster University, Toronto, Canada

b Brock University, St. Catharines, Canada

c Zentrum für Europäische Wirtschaftsforschung (ZEW), Mannheim, and Frankfurt

School of Finance \& Management, Frankfurt/Main, Germany. Email:

schroeder@zew.de. 


\section{Introduction}

Abundant research has documented the pitfalls of overconfidence in financial decisionmaking. For example, investors so affected are likely to trade too much (e.g., Barber and Odean (2000)) and under-diversify (Goetzmann and Kumar (2008)), while susceptible managers are prone to excessive M\&A activity (Malmendier and Tate (2008)) and market entry (Camerer and Lovallo (1999)). Daniel Kahneman, in his recent bestseller Thinking, Fast and Slow (2011), argues that professional forecasters are often bested by simple algorithms because they "try to be too clever, think outside the box, and consider complex combinations of features in making their predictions (p. 224)." This is another way of saying that they are overconfident: they believe they know more than they actually do.

While forecast disagreement can occur because of heterogeneity in information, information-updating frequency and model choice (Capistran and Timmermann (2009a)), behavioral bias might also contribute. The purpose of this paper is to explore the impact of overconfidence on forecasting stock market returns in the context of surveys of professional forecasters. The questions we ask ourselves are these. Does overconfidence weaken forecast accuracy? And, given that there is heterogeneity in performance in part induced by heterogeneity in overconfidence, is there a payoff to filtering out weaker forecasters to improve survey accuracy, where weakness is based either on past performance or the tendency to exhibit markers of overconfidence?

Excess market returns have proved to be notoriously difficult to predict out of sample. While there is an extensive literature documenting return predictability within sample using such fundamental variables as dividend yields, interest rates and term spreads, as pointed out by Goyal and Welch (2008), this has not translated into out-of-sample performance as (typically) measured by out-of-sample $\mathrm{R}^{2}\left(\mathrm{OS}-\mathrm{R}^{2}\right)$ relative to a naïve 
benchmark such as the historical average equity premium. ${ }^{1}$ Nevertheless Rapach, Strauss and Zhou (2010) have shown that a combination forecast methodology whereby several predictive variables are optimally combined can lead to a modicum of out-ofsample success. The same holds in Ferreira and Santa-Clara (2011) where the components of stock market returns are predicted separately. Nevertheless predictability is modest, in the former case being less than $4 \%$ (using quarterly data) and in the latter case less than $2 \%$ (using monthly).

While it is logical to expect that panels of professional forecasters, not only with such predictive variables at their disposal but also armed with experiential judgment, should easily be able to outperform naïve benchmarks, the Kahneman perspective encourages skepticism in this regard. Take the ZEW survey in Germany, which since February 2003 has solicited point forecasts for the DAX. ${ }^{2}$ While the mean forecast of the excess market return coming from this survey produces OS- $\mathrm{R}^{2}$ of $6.19 \%$ (with $p$-value $=0.073$ ) for March 2003-June 2010, success is concentrated in the first year as OS- $\mathrm{R}^{2}=1.09 \%(p$ value $=0.239$ ) during February 2004-June 2010.3

Some forecasters are weaker than others and these may skew the consensus. We conjecture that weak forecasters may be weak in part because they are more overconfident than other forecasters. One possibility is that, relying too much on intuition, they have a tendency to make extreme forecasts. Denrell and Fang (2010) document that those who have made a very accurate recent prediction - since markets are volatile this often implies an extreme prediction - are likely to be inferior forecasters going forward. Indeed our data indicate that survey respondents with higher forecast standard deviations have higher mean squared prediction errors (MSPEs).

\footnotetext{
1 See Neely, Rapach, Tu and Zhou (2010) for many references on return predictability.

2 The DAX is an index composed of the 30 largest and most important German companies traded on the German Stock Exchange in Frankfurt.

${ }^{3}$ The ZEW survey actually requests six-month DAX forecasts. The reported OS-R ${ }^{2}$ s are based on imputed one-month forecasts (as described below) so (given this imputation) the February 2003 survey solicits forecasts for March 2003.
} 
Overconfidence can also manifest itself in the tendency to be too sure of one's views, leading to overly narrow confidence intervals. ${ }^{4}$ This tendency is echoed in the model of Daniel, Hirshleifer and Subrahmanyam (1998), where overconfident investors put too much stock in private information and exert pressure on prices in the direction of their information, with the result that if such investors dominate markets overreaction and eventual reversal in security prices can ensue. We further document that forecasters whose confidence intervals are wide enough to contain the eventual DAX realization more often than other forecasters are better forecasters in the sense that they have lower MSPEs. This is not tautological because better forecasters actually have narrower confidence bounds.

Next consensus forecast improvement is considered. We show that filtering out from the survey inferior forecasters can lead to modest but statistically significant improvements in accuracy. For example, if we drop the $30 \%$ of forecasters whose prior MSPEs over the preceding three forecasts was highest, OS- $\mathrm{R}^{2}$ reaches $4.18 \%$, which is significant at $2 \%$. It is not obvious that this should be so since one might expect that inferior forecasts would be as likely to be too high (relative to the realization) as too low. Evidently, some error clustering is occurring, consistent with what has been found for analysts (Hirshleifer and Teoh (2003)). We also document that there is a payoff to dropping forecasters without regard to past performance but who exhibit one marker of overconfidence, namely the tendency to make extreme forecasts. For example, if we drop the $70 \%$ of forecasters whose prior forecast volatility is highest over the preceding 12 months, OS- $\mathrm{R}^{2}$ reaches $4.43 \%$, which is significant at $3 \%$.

In what follows, we begin by providing appropriate background on the ZEW DAX survey. In section 3 we explore the characteristics of successful forecasters and the contributing role of overconfidence. In the penultimate section, we document that

\footnotetext{
${ }^{4}$ Deaves, Lüders and Schröder (2010) have previously documented that the ZEW forecasters are overconfident in this sense. Ben-David, Graham and Harvey (2013) have performed a similar exercise using a U.S. panel of market forecasts.
} 
filtering out weaker forecasters can lead to meaningful out-of-sample predictability. Finally, in section 5, we discuss our findings and sum up.

\section{ZEW survey}

The ZEW Finanzmarkttest is a monthly survey of over 300 private sector forecasters in Germany. From 1991 to the present it has solicited predicted directional changes (rise/fall/unchanged) in a series of key macroeconomic and financial market variables for the key industrialized economies as of six months in the future. ${ }^{5}$ Starting in February 2003, ZEW survey respondents were also asked to provide quantitative forecasts and confidence intervals for the DAX. Specifically, point estimates for the DAX six months in the future, as well as lower and upper bounds forming $90 \%$ confidence intervals began to be solicited. These are the forecasts that we investigate here. ${ }^{6}$ The cleaned dataset has over 20,000 forecaster-survey observations, with a survey minimum/mean/maximum of 135/228/269.

To avoid the overlapping data problem inherent in the fact that forecasts are made monthly for six-month-ahead DAX levels, we here follow the methodology of Deaves, Lüders and Schröder (2010), where one-month point forecasts and 90\% confidence intervals are imputed from six-month. It is assumed that forecasters believe that the growth rate in the DAX will be constant over the next six months. More specifically, letting L6, F6 and U6 be the six-month interval lower bound, forecast point estimate and interval upper bound respectively, the one-month forecast point estimate (F1) is calculated as:

\footnotetext{
${ }^{5}$ Most of these individuals work for a commercial bank, investment bank, insurance company or investment department of a large German company. For example, participants are asked to predict the inflation rate, long-term and short-term interest rates, economic activity, and stock market levels for these countries.

${ }^{6}$ The final survey in our dataset is May 2010.
} 


$$
\text { (1) } F 1=\left(\frac{F 6}{D A X 0}\right)^{1 / 6} * D A X 0 \text {, }
$$

where DAX0 is the (respondent-specific) current level of the DAX. On the assumption of i.i.d. DAX one-month returns, the standard deviation of one-month returns is $1 / \sqrt{ } 6$ times the six-month standard deviation. Confidence intervals are chosen to reflect what is believed to be the correct number of standard deviations on each side of the point estimate, as follows:

$$
\begin{aligned}
& \text { (2) } U 1=F 1 *\left(\frac{U 6}{F 6}\right)^{\frac{1}{\sqrt{6}}} \\
& \text { (3) } L 1=F 1 *\left(\frac{L 6}{F 6}\right)^{\frac{1}{\sqrt{6}}} .
\end{aligned}
$$

Respondents typically are given several weeks to make their forecasts, with first solicitation occurring usually near the end of the preceding month. For example, for the September 2004 survey the first received response was on August 28, and the last on September 14. For these reasons, equations (1)-(3) require adjustment. Since they are not told to do otherwise, logically respondents would be making their forecasts for exactly six months in the future. If we use these equations without adjustment, respondents' imputed one-month forecasts (and intervals) would be for different DAX dates and thus would not be comparable. The way to obviate this problem is to use a respondent-specific imputation that doesn't generate a one-month ahead forecast (and interval) but rather yields a one-month-ahead-of-the-end-of-forecast-month forecast (and interval), as follows:

$$
\begin{gathered}
\text { (1a) } F 1 a=\left(\frac{F 6}{D A X 0}\right)^{(30+d) / 180 * D A X 0} \\
\text { (2a) } U 1 a=F 1 a *\left(\frac{U 6}{F 6}\right)^{\sqrt{\frac{30+d}{180}}}
\end{gathered}
$$




$$
\text { (3a) } L 1 a=F 1 a *\left(\frac{L 6}{F 6}\right)^{\sqrt{\frac{30+d}{180}}} \text {, }
$$

where $d$ is the number of days from forecast receipt to the end of the forecast month. Averaging subsets of these imputed forecasts provides the ZEW consensus forecasts that are investigated here.

\section{Characteristics of successful forecasters}

In this section we explore the characteristics of successful forecasters, where forecast success is calculated using MSPE. Certain of the variables considered are logical ex ante markers of superior performance, while others are potentially linked to overconfidence. Table 1 summarizes our expectations.

Beginning with logical ex ante markers of superior performance, as described in section 2 , forecasts are made at different times. Those made later, when more information is likely to be available, would be expected to be better forecasts. Cross-sectionally, individuals tend to have different survey response habits, with some tending to forecast early and others doing so towards the end of the survey month. STALENESS_MEAN, which is defined as the average number of days prior to the end of the survey month the forecaster in question submits her forecast, captures this. The expectation is that those contributing early and thus having higher STALENESS_MEAN will tend to have higher MSPE.

Second, forecasters submit not only point forecasts (which are used to assess MSPE) but also $90 \%$ confidence intervals surrounding their point forecasts. Logically those who feel they have a better sense of where the DAX is going should submit narrower confidence intervals. Thus average (scaled) confidence interval width (CONF_INT_MEAN), defined as (U6-L6)/DAX0, provides information on confidence. 
Importantly, this is not the same as overconfidence, which requires a comparison of perceived and revealed ability. The expectation is that those with lower CONF_INT_MEAN will tend to have lower MSPE. Of course it is possible that their confidence is entirely unfounded, in which case there will be no impact.

Third, the tendency to produce extreme forecasts thereby relying to a great extent on one's own intuition points in the direction of overconfidence. Consistent with Denrell and Fang (2010), the expectation is that those whose forecasts tend to be more variable (i.e., have a higher standard deviation $(S D)$ ) will be weaker forecasters. Such a relationship is far from obvious, since, given the volatility that exists in stock indexes, a "perfect foresight" forecaster will have extremely variable forecasts. It is expected that SD and MSPE are positively related.

Finally, frequent submission is likely to be a signal of attention. On the other hand, consistent with the inattention model of Peng and Xiong (2006), those participating sporadically are signaling inattention and perhaps a reduced ability to see where markets are moving. We define EXPERIENCE as the overall number of forecasts submitted during the sample, with the expectation that higher EXPERIENCE is associated with lower MSPE. Diminishing returns seem likely: logically going from 10 forecasts to 20 is a stronger incremental signal of interest than going from 50 to 60 , since everyone responding 50 times or more is exhibiting commitment. For these reasons we perform not only regressions with EXPERIENCE but also those including a squared term (EXPERIENCE_2), with the expectation that the coefficient on the latter should be positive to reflect convexity vs. MSPE.

Table 2 reveals whether the data conform to expectations. ${ }^{7}$ Its four panels differ in the minimum number of forecasts that a forecaster must submit in order to remain in the

\footnotetext{
${ }^{7}$ In unreported results, a version of Table 2 that excludes 2007-08, a tumultuous period in financial markets, is broadly similar to what is reported here.
} 
sample, with minima ranging from $n=5$ to $n=30$. While each panel displays three regressions, initially we focus on the first two, with the first positing a linear relationship for EXPERIENCE, and the second by including a squared term allowing for diminishing returns. Turning to regression (2) in Panel B (where forecasters are only included if they have made at least 10 forecasts over the full sample and non-linearity in EXPERIENCE is allowed for), we see the coefficients line up exactly as anticipated, with all variables being of the anticipated sign and statistically significant at $1 \%$ or very close to it. Regression (1) from the same panel is comparable, with a reduced significance level for EXPERIENCE because linearity is imposed.

The other panels can be thought of as robustness checks. STALENESS_MEAN, CONF_INT_MEAN, and the overconfidence marker SD are extremely robust, with all other coefficients indicating significance in the anticipated direction at $10 \%$ or better. As for EXPERIENCE, both the unsquared and squared terms become insignificant for $\mathrm{n}=30$, which should perhaps not be surprising because given non-linearity most of the meaningful impact of EXPERIENCE comes for more moderate EXPERIENCE levels.

As a further robustness check, we re-estimate regression (2) by replacing CONF_INT_MEAN with average relative imputed individual volatility, or RELATIVE_IMPUTED_IND_VOL_MEAN. The latter variable begins with IMPUTED_IND_VOL, namely the conversion of respondents' confidence intervals into individual volatility estimates by using the Davidson and Cooper (1976) method to recover respondent-specific probability distributions under normality: ${ }^{8}$

$$
\text { (4) IMPUTE } D_{I N D_{V O L}}=\frac{(U 1 a-L 1 a)}{3.2 * D A X 0} \text {. }
$$

\footnotetext{
8 See Pearson and Tukey (1965), Moder and Rodgers (1968), and Ben-David, Graham, and Harvey (2013). Equation (4) is based on the fact that respondents' confident intervals are $90 \%$.
} 
This variable is calculated for each forecaster in every survey month. We then standardize relative to all forecasters participating in the same survey month. Finally, we calculate for all forecasters the average across all months for which there was participation. Regression (3) appears in the third column. Consistent with regression (2), survey respondents with higher average relative imputed individual volatilities have higher MSPEs.

The miscalibration-based variant of overconfidence, which exists when $x \%$ confidence intervals (subject to sampling error) contain fewer than $x \%$ correct answers, can be directly calculated from the data. Using the first two years of the ZEW forecasts, Deaves, Lüders and Schröder (2010) found that the average forecaster in this dataset was egregiously overconfident in this sense, but, consistent with learning, they adjusted their confidence interval widths depending on past success. Here we take a different perspective. If overconfidence gets in the way of judicious forecasting, then we would expect more overconfident forecasters to have higher MSPEs. Letting HIT_PERCENTAGE be defined as the percentage of the time one's (imputed) onemonth confidence interval contains the eventual value of the DAX, with lower values indicating higher overconfidence, according to this argument HIT_PERCENTAGE should be negatively related to MSPE.

While on the surface it might appear viable to introduce HIT_PERCENTAGE as an additional explanatory variable in the MSPE regressions, there is a problem in doing so. Once we control for the average confidence width (CONF_INT_MEAN), HIT_PERCENTAGE will by construction be negatively related to MSPE. This is because holding constant interval width a successful forecaster will almost certainly have more "hits" than an unsuccessful one. Matters are quite different however if we relate HIT_PERCENTAGE to MSPE without controlling for CONF_INT_MEAN. It is helpful to roughly partition overconfidence as follows: 
(5) OVERCONFIDENCE = KNOWLEDGE PERCEPTION - ACTUAL KNOWLEDGE.

Overconfidence exists when one's perception of knowledge (i.e., one's confidence) exceeds one's actual knowledge. More precisely, an increase in KNOWLEDGE PERCEPTION (in the present context, confidence interval shrinkage) reflects ceteris paribus higher overconfidence, while an increase in ACTUAL KNOWLEDGE (in the present context, lower MSPE) reflects ceteris paribus lower overconfidence. Since the regression results show that confidence interval width and MSPE are positively related (i.e., low-MSPE forecasters not only have high perceptions of their knowledge but also high levels of actual knowledge), the relationship between overconfidence (i.e., lower HIT_PERCENTAGE) and revealed MSPE is an open question. We conjecture a negative relationship between overconfidence and forecast performance (revealed MSPE), which is logical if the tendency to be overly certain of one's view induces one to economize on effort.

To test this conjecture, terciles based on MSPEs are formed. These terciles are designated as 'High,' 'Medium,' and 'Low' based on MSPEs, with the High group containing the highest-MSPE forecasters and the Low group containing the lowestMSPE forecasters. For each tercile, in Table3 HIT_PERCENTAGEs are calculated for the same four cross-sectional samples as in Table 2. Further, the last column shows a $t$-test for the difference in means between the extreme groups. If overconfident forecasters tend to make weak forecasts, then this would imply that High forecasters will have a lower HIT_PERCENTAGE than Low forecasters. There is evidence to this effect. In all four cases, Low has a higher average HIT_PERCENTAGE than does High. When there are at least 5-20 survey responses, the difference is statistically significant at $10 \%$ or better. 


\section{Filtering the ZEW survey}

There are compelling reasons to pool forecasts (Timmermann (2009)). For example, if different forecasts use non-matching sources of information, efficient information aggregation may result. And diverse forecasting techniques may be affected differently by structural breaks. While in theory weighting individual forecasts is appealing, a simple equal-weighted approach often dominates because of parameter estimation error. Moreover, more subtle techniques such as least squares estimation of weights are difficult to operationalize with an unbalanced panel such as the one studied here (Capistran and Timmermann (2009b)). Trimming or filtering out poor forecasters (or models) who mostly contribute noise has been shown to improve forecast combinations (e.g., Aiolfi and Favero (2005)). ${ }^{9}$

Here we consider the mean ZEW DAX forecast either with or without filtering based on prior performance. ${ }^{10}$ The purpose is to investigate whether elimination of some of the weaker forecasters improves forecast combination accuracy. While we later document that one factor driving inferiority is overconfidence, for now the focus is merely on unconditional performance. In order to generate out-of-sample forecasts it is important that filtering be based on known information. Specifically we eliminate the $z \%$ of forecasters whose prior MSPEs fall in the bottom $z \%$ of all forecasters participating in a given month. We consider increments of 10\% (10-90\%) along with 95\%, 99\% and "All but best." The latter means that only the forecaster with the lowest prior MSPE is kept. ${ }^{11}$

When utilizing past information, the two choices are a recursive or rolling window. ${ }^{12}$

\footnotetext{
9 Though unexplored here, further improvement may also arise by combining survey data with time series models (Pesaran and Weale (2006)).

${ }^{10}$ All results presented here are little affected by using the median instead of the mean.

${ }^{11}$ For the $99 \%$ filter, typically two forecasters remain, though with ties the number can reach seven.

12 Note that we say "window" we mean the number of monthly forecasts that we look back at to assess performance prior to the forecast in question. Thus this forecast is not included in the window.
} 
In the former case, all previous data are conditioned on while in the latter a constantlength window is maintained. The advantage of the former is that all information is used, but the disadvantage is some of this information might be so stale that it is best ignored. For example, suppose there are two ways to forecast the DAX, one primarily technical and the other primarily fundamental, with some forecasters employing the first approach and others the second. ${ }^{13}$ Further suppose that the return generating function for the DAX is regime-dependent. Under the first regime, a technical approach would generate better forecasts, while under the second regime a fundamental approach would outperform. The problem with using a recursive approach is that it is less sensitive to the current regime since it could well be the case that a forecaster looks good because her technique performed well early in the sample when one regime was in place but her recent performance has been weaker now that a second regime is in effect. By varying the length of the rolling window one can get a sense of the optimal amount of past data to condition on. In truth, however, such a comparison is going to have an in-sample flavor, as there is no guarantee that this optimal window length will continue to be optimal going forward.

To evaluate the out-of-sample performance of the ZEW mean equity premium forecast, we calculate OS- $\mathrm{R}^{2}$, after Campbell and Thompson (2008). This calculation requires a forecast methodology against which the ZEW forecast is compared. The simplest benchmark is the mean realized equity premium. Against such a benchmark, OS- $\mathrm{R}^{2}$ is calculated as follows:

$$
\text { (6) } \left.R_{O S}^{2}=1-\frac{\sum_{k=q_{0}+1}^{q}\left(r_{m+k}-\hat{r}_{m+k}^{Z E W_{\text {Mean }}}\right)^{2}}{\sum_{k=q_{0}+1}^{q}\left(r_{m+k}-\bar{r}_{m+k}^{\text {Hist }}\right. \text { Mean }}\right)^{2} \text {, }
$$

where $m$ is the number of in-sample observations; $q$ is number of out-of-sample

${ }^{13}$ Dick and Menkhoff (2013) use this categorization in investigating ZEW exchange rate forecasts. 
observations; $q_{0}$ is the initial out-of-sample forecast of the equity premium; $r_{m+k}$ is the realized equity premium at $m+k$ in the out-of-sample period; $\hat{r}_{m+k}^{Z E W_{-} \text {Mean }}$ is the ZEW mean out-of-sample equity premium forecast at $m+k$; and $\bar{r}_{m+k}^{\text {Hist_Mean }}$ is the historical mean equity premium calculated using data up to $m+k$. Note that $R_{O S}^{2}$ gauges the proportional reduction in MSPE for the ZEW mean forecast relative to the benchmark. ${ }^{14}$

When $R_{O S}^{2}>0$, the ZEW forecast on average outperforms the historical mean forecast according to the MSPE metric. ${ }^{15}$ Based on Clark and West (2007), the null hypothesis that $R_{O S}^{2} \leq 0$ is tested against the alternative hypothesis that $R_{O S}^{2}>0$ in two steps. First, define the MSPE-adjusted statistic as follows:

$$
\text { (7) } f_{t+1}=\left(r_{t+1}-\bar{r}_{t+1}^{\text {Hist_Mean }}\right)^{2}-\left[\left(r_{t+1}-\hat{r}_{t+1}^{\text {ZEW_Mean }}\right)^{2}-\left(\bar{r}_{t+1}^{\text {Hist_Mean }}-\hat{r}_{t+1}^{\text {ZEW_Mean }}\right)^{2}\right] \text {. }
$$

Second, regress $\left\{f_{s+1}\right\}_{s=m+q_{0}}^{T-1}$ on a constant. And, finally, calculate the $t$-statistic of this constant. A $p$-value for a one-sided (upper-tail) test is then obtained with the standard normal distribution.

Figure 1 displays both OS-R ${ }^{2} \mathrm{~S}$ and corresponding $p$-values for one-, two- and three-year recursive windows. Specifically, in the (say) two-year case, for possible inclusion in the consensus respondents are ranked based on MSPE over the first 24 surveys and if they are in the lowest $z \%$ they remain in the sample for the $25^{\text {th }}$ survey. Moving forward one period, to form the $26^{\text {th }}$ survey consensus, the holdout sample is based on the first 25 forecasts, and so on. Note that to be considered for inclusion we impose the screen that at least 10 forecasts must have been made by a forecaster during the holdout window (i.e., prior to the forecast to be evaluated). It can be observed in Figure 1 that while

\footnotetext{
14 The benchmark forecast is the historical average of monthly excess returns. It is the historical mean taken over all available excess returns at each point of time for recursive windows. For rolling windows, the historical mean benchmark is computed over a corresponding fixed window size.

15 Throughout this paper, monthly rate of 3-month Frankfurt Interbank Offered Rate (FIBOR3M) is used as the risk-free rate to calculate the mean one-month-ahead forecast of the excess market return.
} 
filtering improves matters somewhat the OS- $\mathrm{R}^{2}$ is never significant even at $10 \% .{ }^{16}$ Evidently, there is little obvious value added in using a recursive approach. ${ }^{17}$

In Figure 2 the same one-, two- and three-year windows as in Figure 1 are utilized, this time though using a rolling methodology. Again, we employ the screen that at least 10 forecasts over the rolling window must have been made. The first evaluated forecast is done in an identical fashion to the recursive approach, but moving forward the window size is kept constant, implying that early observations are ignored in forecast evaluation. Again, in all cases at least 10 observations over the preceding one, two or three years are required in order to be considered for inclusion. A rolling one-year approach reveals some improvement vs. no filtering with OS- $\mathrm{R}^{2} \mathrm{~s}$ for $30-50 \%$ filters ranging from $2.66-3.38 \%$ with $p$-values at $10 \%$ or better. The superiority of a one-year vs. two- and three-year windows suggests that it is best to limit the window length so that forecasting success in the more distant past is ignored.

Figure 3 investigates how narrow the window should be in order to maximize combination forecast improvement. Four approaches are displayed. The first (Min_10_for_12) repeats the rolling one-year window used in Figure 2 as a point of departure. The other three filters employ rolling windows of six months (Min_5_for_6), three months (Min_2_for_3) and one month (Min_1_for_1). It is also necessary to specify a minimum number of prior forecasts in the rolling window (again noting that the window does not include the forecast under consideration). For six months/three months/one month, the minimum is five/two/one. To interpret the Min_1_for_1 case, included forecasters must participate in two consecutive surveys, the one whose success is being examined as well as the one immediately preceding (where past success is based on how close the latter forecast was to the eventual DAX).

\footnotetext{
${ }^{16}$ As it were, there are two filters. The first, which to avoid confusion we call a screen, requires a sufficiently long track record so that past performance can be assessed, and the second drops people based on poor past performance.

17 Note that even the $0 \%$ filter is based on the "minimum of 10 " restriction.
} 
Beginning with Min_1_for_1, the highest OS-R ${ }^{2}$ observed in Figure $3(6.75 \%, p$ value $=0.063$ ) is without filtering. Thus, exclusion of forecasters is not helpful: in fact it worsens matters, and for filters of $70 \%$ or more it is very much counterproductive. This should not be surprising since a track record of a single previous forecast (beyond the one under examination) is naturally rife with noise, and is clearly subject to the Denrell and Fang (2010) extreme-forecast success critique. Nevertheless it should be noted that there is a marginal gain from attention due to the fact that only those forecasters participating twice in a row are considered. The reference point in this regard is an OS$\mathrm{R}^{2}$ of $6.19 \%(p$-value $=0.073)$, which applies to the case when we only assess the mean forecast without any past history requirement.

As for the other two (new) cases in Figure 3, filtering improves matters for both the rather short 6-month and 3-month rolling windows. For example, for the very narrow three-month window (where we insist that a forecaster was active for the majority (i.e., 2 of 3) of prior forecasts), the OS-R ${ }^{2}$ s range from $3.35-4.18 \%$ for $10-50 \%$ filters. These values are statistically significant at the $5 \%$ level when compared to the historical mean.

Related to Figure 3 is Figure 4. Figure 4 ascertains the success of filtering, utilizing the same four approaches, but now the unfiltered mean forecast (rather than the historical mean) is the benchmark against which we compare filtered mean forecasts (which is why we begin at $10 \%)$. Broadly speaking, filtering out inferior forecasters is somewhat helpful, with a moderate amount of filtering producing the best results. Again, for the Min_2_for_3 case, the OS-R ${ }^{2}$ (vs. no filtering) at a $10 \%$ filter is $1.45 \%$ with a $p$-value of 0.090 .18

${ }^{18}$ For the Min_5_for_6 case, the OS-R (vs. no filtering) at a $20 \%$ filter is $2.11 \%$ with a $p$-value of 0.087 . For the Min_10_for_12 case, the OS-R ${ }^{2}$ (vs. no filtering) at a $10 \%$ filter is $1.50 \%$ with a $p$-value of 0.078 . For brevity, we do not provide the "vs. $\%$ filter" analogous (to Figures 1 and 2) charts. In a nutshell 10\% filtering is effective (at $10 \%$ or close to it) for the three recursive approaches. On the other hand, filtering does not pay off for the 24-month and 36-month rolling windows. 
Next we investigate whether those weaker forecasters who are filtered out are dropped in part because of their overconfidence. Turning to Table 4, which employs the screen that a forecaster for potential inclusion must have made at least five forecasts over the previous six months, we provide the average levels (both mean and median) of relevant variables for three groups of forecasters, designated as 'Most,' 'Between' and 'Least,' based on the percentage of the time that a forecaster is filtered out over the sample period (where the Most group contains individuals who are filtered out the most and the Least group contains individuals who are filtered out the least). Focusing on variables from Table 2, it is salient that forecasters with narrow forecast intervals recall such forecasters are signaling confidence - are less likely to be filtered out. Further, one indicator of overconfidence, the standard deviation of point estimates, is also positively associated with a reduced likelihood to be included in the survey. While Table 2 suggests that overconfident forecasters (in the sense that they release extreme forecasts) are weak forecasters (i.e., they have higher MSPEs), Table 4 suggests that those forecasters who are often filtered out based on prior MSPEs also turn out to be overconfident forecasters (in the sense that their forecasts are too extreme).

Apart from academic interest, what if were considering hiring various individuals in a forecasting capacity, but while we had no track record of their forecasting performance we did possess proxies (perhaps obtained through the administration of a questionnaire) for various manifestations of overconfidence. The results presented here impel us to think twice before retaining applicant forecasters who reveal themselves to be overconfident.

Corroboration of this view exists in Figure 5, where forecasters are filtered out not because of previous forecasting performance but because of prior point forecast standard deviation. It is apparent that there is a payoff to filtering out forecasters who display overconfidence through their past tendency to make extreme forecasts. In Figure 5, six-month to three-year rolling windows are used. Take the one-year rolling 
window: while the OS- $\mathrm{R}^{2}$ is close to zero, using $60-90 \%$ filters generates OS- $\mathrm{R}^{2} \mathrm{~s}$ of $3.92-$ $4.43 \%$ which are statistically significant at less than $5 \%$.

\section{Discussion and concluding remarks}

The ability to forecast market returns is critical for many decision-makers. It matters for market timing, asset allocation, pension fund deficit calculation and corporate planning. While it is recognized that returns have at best a modest predictable component, any improvements that can be garnered over such naïve models as the short rate plus the average realized equity premium are without doubt worth pursuing. Panels of expert forecasters are a ready source of informed opinion, but it is not clear how to make the best use of panel data.

We have considered how overconfidence impacts forecast performance. Overconfidence as proxied by the tendency to make extreme forecasts leads to poor performance. Further, controlling for the fact that good forecasters have some knowledge of their skill which causes them to generate more narrow confidence intervals, it is still true that overconfidence as proxied by the hit ratio (i.e., percentage of the time that an interval contains the eventual realization) is associated with poor performance. It is beneficial to have information on the sources of forecast weakness because if one has such information but the forecaster under the microscope has an insufficient track record one can still make educated guesses about future performance.

Given forecaster heterogeneity it is logical to explore whether filtering out weak forecasters is a viable strategy. Filtering can be done directly by conditioning on past performance. Particularly useful when performance information is sparse is the fact that conditioning can also be done indirectly by taking into account overconfidence markers. Fairly short rolling windows, which delicately balance ignoring relevant information and noise reduction, work best. 


\section{REFERENCES}

Aiolfi, M., and C. A. Favero, 2005, Model uncertainty, thick modelling and the predictability of stock returns, Journal of Forecasting 24, 233-54.

Barber, B., and T. Odean, 2000, Trading is hazardous to your wealth: The common stock investment performance of individual investors, Journal of Finance 55, 773-806.

Ben-David, I., J. R. Graham, and C. R. Harvey, 2013, Managerial miscalibration, Quarterly Journal of Economics, Forthcoming.

Camerer, C. F., and D. Lovallo, 1999, Overconfidence and excess entry: An experimental approach, American Economic Review 89, 306-18.

Campbell, J. Y., and S. B. Thompson, 2008, Predicting excess stock returns out of sample: Can anything beat the historical average? Review of Financial Studies 21, 1509-1531.

Capistran, C., and A. Timmermann, 2009a, Disagreement and biases in inflation expectations, Journal of Money, Credit and Banking 41, 365-96.

Capistran, C., and A. Timmermann, 2009b, Forecast combination with entry and exit of experts, Journal of Business and Economic Statistics 27, 428-40.

Clark, T. E., and K. D. West, 2007, Approximately normal tests for equal predictive accuracy in nested models, Journal of Econometrics 138, 291-311.

Daniel, K., D. Hirshleifer, and A. Subrahmanyam, 1998, Investor psychology and security market under- and overreactions, Journal of Finance 53, 1839-85.

Davidson, L. B., and D. O. Cooper, 1976, A simple way of developing a probability distribution of present value, Journal of Petroleum Technology, September, 10691078.

Deaves, R., E. Lüders, and M. Schröder, 2010, The dynamics of overconfidence: Evidence from stock market forecasters, Journal of Economic Behavior and Organization 75, 402-12.

Denrell, J., and C. Fang, 2010, Predicting the next best thing: Success as a signal of poor judgment, Management Science 56, 1653-67.

Dick, C. D., and L. Menkhoff, 2013, Exchange rate expectations of chartists and fundamentalists, Working paper.

Ferreira, M. A., and P. Santa-Clara, 2011, Forecasting stock market returns: The sum of the parts is more than the whole, Journal of Financial Economics 100, 514-37.

Goetzmann, W. N., and A. Kumar, 2008, Equity portfolio diversification, Review of Finance 12, 433-63. 
Goyal, A., and I. Welch, 2008, A comprehensive look at the empirical performance of equity premium prediction, Review of Financial Studies 21, 1455-508.

Hirshleifer, D., and S. H. Teoh, 2003, Herd behavior and cascading in capital markets: A review and synthesis, European Financial Management 9, 25-66.

Kahneman, D., 2011. Thinking, Fast and Slow (Farrar, Straus and Giroux, New York).

Malmendier, U., and G. Tate, 2008, Who makes acquisitions? CEO overconfidence and the market's reaction, Journal of Financial Economics.

Moder, J. J., and Rodgers, E. G., 1968, Judgment estimates of the moments of PERT Type distributions, Management Science 15, B76-B83.

Neely, C. J., D. E. Rapach, J. Tu, and G. Zhou, 2010, Out-of-sample equity premium prediction: Economic fundamentals vs. moving-average rules, Working paper.

Pearson, E. S., and Tukey, J. W., 1965, Approximate means and standard deviations based on distances between percentage points of frequency curves, Biometrika 52, 533-546.

Peng, L., and W. Xiong, 2006, Investor inattention, overconfidence and category learning, Journal of Financial Economics 80, 563-602.

Pesaran, M. H., and M. Weale, 2006, Survey expectations, in G. Elliott, C. W. J. Granger, and A. Timmermann, eds.: Handbook of Economic Forecasting, Volume 1 (Elsevier B. V.).

Rapach, D. E., J. K. Strauss, and G. Zhou, 2010, Out-of-sample equity prediction: Combination forecasts and links to the real economy, Review of Financial Studies $23,821-62$.

Timmermann, A., 2006, Forecast combinations, in G. Elliott, C. W. J. Granger, and A. Timmermann, eds.: Handbook of Economic Forecasting, Volume 1 (Elsevier B. V.). 


\section{TABLE 1: Sign expectations of determinants of MSPE}

This table presents sign expectations of determinants of MSPEs. STALENESS_MEAN is the average number of days prior to the end of the survey month the forecaster in question submits his or her forecast. CONF_INT_MEAN is defined as (U6-L6)/DAX0, or the difference between the six-month interval upper bound and lower bound deflated by the current level of the DAX. $S D$ is the standard deviation of point forecasts. EXPERIENCE is the overall number of forecasts submitted during the sample. EXPERIENCE_2 is EXPERIENCE squared.

\begin{tabular}{lc}
\hline Independent variables & Expected sign \\
\hline STALENESS_MEAN & + \\
CONF_INT_MEAN & + \\
SD & + \\
EXPERIENCE & - \\
EXPERIENCE_2 & + \\
\hline
\end{tabular}




\section{TABLE 2: Cross-sectional MSPE regressions}

This table reports the estimated coefficients from the cross-sectional regressions of MSPE on various potential determinants. The dependent variable is scaled by $10^{4}$. STALENESS_MEAN is the average number of days prior to the end of the survey month the forecaster in question submits his or her forecast. CONF_INT_MEAN is defined as the average of (U6-L6)/DAX0, the difference between the six-month interval upper bound and lower bound deflated by the current level of the DAX for each forecaster. $S D$ is the standard deviation of point forecasts over the sample. EXPERIENCE is the overall number of forecasts submitted during the sample. EXPERIENCE_2 is EXPERIENCE squared. RELATIVE_IMPUTED_IND_VOL_MEAN is calculated in two steps (as in Ben-David, Graham, and Harvey (2013)). First, for each forecaster in every survey month, we convert respondents' confidence intervals into individual volatility estimates by using the Davidson and Cooper (1976) method to recover respondent-specific probability distributions under normality. Second, we standardize them relative to all forecasters participating in the same survey month and then average across all months for which there was participation. Panels A through D differ in the minimum number of forecasts that a forecaster must submit in order to remain in the sample, with minima of $\mathrm{n}=5,10,20$, and 30 , respectively. The $t$-statistics are reported below the coefficients and corrected for heteroscedasticity using the White (1980) correction. Note that ***, ${ }^{* *}$, and * indicate significance at $1 \%, 5 \%$, and $10 \%$, respectively.

\begin{tabular}{lccc}
\hline \multicolumn{4}{c}{ Panel A: At least 5 survey responses } \\
\hline Independent variables & $(1)$ & $(2)$ & $(3)$ \\
\hline & & & \\
STALENESS_MEAN & $0.740^{* * *}$ & $0.817^{* * *}$ & $0.751^{* * *}$ \\
& $(4.274)$ & $(4.621)$ & $(4.473)$ \\
CONF_INT_MEAN & $30.769^{* * *}$ & $28.518^{* * *}$ & \\
SD & $(2.979)$ & $(2.920)$ & \\
& $0.012^{* * *}$ & $0.013^{* * *}$ & $0.013^{* * *}$ \\
EXPERIENCE & $(2.830)$ & $(3.248)$ & $(3.253)$ \\
& $-0.108^{* * *}$ & $-0.701^{* * *}$ & $-0.731^{* * *}$ \\
EXPERIENCE_2 & $(-2.754)$ & $(-3.838)$ & $(-3.962)$ \\
& & $0.006^{* * *}$ & $0.006^{* * *}$ \\
RELATIVE_IMPUTED_IND_VOL_MEAN & & $(3.640)$ & $(3.765)$ \\
& & & $2.766^{* *}$ \\
Constant & 7.585 & $16.659^{* * *}$ & $(2.409)$ \\
& $(1.525)$ & $(3.013)$ & $(4.372)$ \\
Observations & & & \\
Adj. R-squared & 381 & 381 & 381 \\
& 0.085 & 0.115 & 0.117 \\
\hline
\end{tabular}




\begin{tabular}{|c|c|c|c|}
\hline \multicolumn{4}{|c|}{ Panel B: At least 10 survey responses } \\
\hline Independent variables & $(1)$ & $(2)$ & (3) \\
\hline STALENESS_MEAN & $\begin{array}{c}0.619^{\star * *} \\
(4.201)\end{array}$ & $\begin{array}{c}0.685^{* * *} \\
(4.689)\end{array}$ & $\begin{array}{c}0.634^{\star * *} \\
(4.412)\end{array}$ \\
\hline CONF_INT_MEAN & $\begin{array}{c}24.189^{* * *} \\
(2.672)\end{array}$ & $\begin{array}{c}22.262^{* *} \\
(2.570)\end{array}$ & \\
\hline SD & $\begin{array}{l}0.013^{* * *} \\
(3.677)\end{array}$ & $\begin{array}{c}0.015^{\star * *} \\
(3.987)\end{array}$ & $\begin{array}{l}0.015^{* * *} \\
(3.965)\end{array}$ \\
\hline EXPERIENCE & $\begin{array}{l}-0.094^{* *} \\
(-2.244)\end{array}$ & $\begin{array}{c}-0.661^{* * *} \\
(-3.594)\end{array}$ & $\begin{array}{c}-0.689^{* * * *} \\
(-3.721)\end{array}$ \\
\hline EXPERIENCE_2 & & $\begin{array}{l}0.005^{* * *} \\
(3.551)\end{array}$ & $\begin{array}{l}0.006^{* * *} \\
(3.687)\end{array}$ \\
\hline RELATIVE_IMPUTED_IND_VOL_MEAN & & & $\begin{array}{l}2.043^{* *} \\
(2.261)\end{array}$ \\
\hline Constant & $\begin{array}{c}8.227 \\
(1.642)\end{array}$ & $\begin{array}{c}17.373^{* * *} \\
(3.276)\end{array}$ & $\begin{array}{c}23.142^{* * *} \\
(4.849)\end{array}$ \\
\hline $\begin{array}{l}\text { Observations } \\
\text { Adj. R-squared }\end{array}$ & $\begin{array}{c}347 \\
0.093\end{array}$ & $\begin{array}{c}347 \\
0.122\end{array}$ & $\begin{array}{c}347 \\
0.122\end{array}$ \\
\hline \multicolumn{4}{|c|}{ Panel C: At least 20 survey responses } \\
\hline Independent variables & $(1)$ & (2) & (3) \\
\hline STALENESS_MEAN & $\begin{array}{c}0.621^{* * *} \\
(4.146)\end{array}$ & $\begin{array}{c}0.724^{* * *} \\
(4.735)\end{array}$ & $\begin{array}{c}0.687^{* * *} \\
(4.553)\end{array}$ \\
\hline CONF_INT_MEAN & $\begin{array}{c}17.781^{* *} \\
(2.051)\end{array}$ & $\begin{array}{c}16.699^{* *} \\
(1.974)\end{array}$ & \\
\hline$S D$ & $\begin{array}{c}0.013^{* * *} \\
(3.431)\end{array}$ & $\begin{array}{c}0.015^{\star * *} \\
(3.670)\end{array}$ & $\begin{array}{l}0.015^{* * *} \\
(3.684)\end{array}$ \\
\hline EXPERIENCE & $\begin{array}{l}-0.080^{*} \\
(-1.692)\end{array}$ & $\begin{array}{c}-0.944^{* * *} \\
(-3.178)\end{array}$ & $\begin{array}{l}-0.960^{* * *} \\
(-3.215)\end{array}$ \\
\hline EXPERIENCE_2 & & $\begin{array}{l}0.008^{* * *} \\
(3.245)\end{array}$ & $\begin{array}{c}0.008^{* * *} \\
(3.285)\end{array}$ \\
\hline RELATIVE_IMPUTED_IND_VOL_MEAN & & & $\begin{array}{l}1.518^{*} \\
(1.852)\end{array}$ \\
\hline Constant & $\begin{array}{l}8.018 \\
(1.463)\end{array}$ & $\begin{array}{c}25.912^{* * *} \\
(3.266)\end{array}$ & $\begin{array}{c}29.883^{* * *} \\
(3.871)\end{array}$ \\
\hline Observations & 296 & 296 & 296 \\
\hline
\end{tabular}




\begin{tabular}{lccc}
\hline \multicolumn{4}{c}{ Panel D: At least 30 survey responses } \\
\hline Independent variables & $(1)$ & $(2)$ & $(3)$ \\
\hline \multirow{2}{*}{ STALENESS_MEAN } & & & \\
& $\left(4.243^{* * *}\right.$ & $0.647^{* * *}$ & $0.610^{* * *}$ \\
CONF_INT_MEAN & $17.028^{* *}$ & $(4.350)$ & $(4.176)$ \\
& $(1.972)$ & $\left(1.9238^{*}\right.$ & \\
SD & $0.014^{* * *}$ & $0.014^{* * *}$ & $0.014^{* * *}$ \\
EXPERIENCE & $(3.612)$ & $(3.671)$ & $(3.706)$ \\
& 0.014 & -0.380 & -0.383 \\
EXPERIENCE_2 & $(0.306)$ & $(-0.951)$ & $(-0.961)$ \\
& & 0.003 & 0.003 \\
RELATIVE_IMPUTED_IND_VOL_MEAN & & $(1.063)$ & $(1.076)$ \\
& & & $1.610^{* *}$ \\
Constant & 1.455 & 10.997 & $(1.976)$ \\
& $(0.270)$ & $(0.982)$ & $(1.407$ \\
Observations & & & \\
Adj. R-squared & 264 & 264 & 264 \\
& 0.123 & 0.125 & 0.130 \\
\hline
\end{tabular}




\section{TABLE 3: Hit percentages for MSPE groups}

This table investigates whether more overconfident forecasters have higher MSPEs. HIT_PERCENTAGE is defined as the percentage of the time one's (imputed) one-month confidence interval contains the eventual value of the DAX, with lower values indicating higher overconfidence. High, Medium, and Low groups based on MSPE are formed, with the High group containing the highest-MSPE forecasters and the Low group the lowest-MSPE forecasters. The last column reports the difference in means between High and Low with a $t$-test for equality. Note that $* * * * *$, and * indicate significance at $1 \%, 5 \%$, and $10 \%$, respectively.

\begin{tabular}{lcccc}
\hline Group based on MSPE & Low & Medium & High & $\begin{array}{c}\text { Difference } \\
\text { (High-Low) }\end{array}$ \\
\hline $\begin{array}{l}\text { Panel A: At least } 5 \text { survey responses } \\
\text { HIT_PERCENTAGE }(\%)\end{array}$ & 51.88 & 51.70 & 47.38 & $-4.50^{* *}$ \\
Panel B: At least 10 survey responses & & & & \\
\hline HIT_PERCENTAGE $(\%)$ & 52.54 & 50.78 & 48.49 & $-4.05^{*}$ \\
Panel C: At least 20 survey responses & & & & \\
\hline HIT_PERCENTAGE $(\%)$ & 51.54 & 50.51 & 46.54 & $-5.00^{* *}$ \\
Panel D: At least 30 survey responses & & & & \\
\hline HIT_PERCENTAGE $(\%)$ & 51.96 & 49.49 & 48.79 & -3.17 \\
\hline
\end{tabular}




\section{TABLE 4: Characteristics of filtered out forecasters}

This table investigates the characteristics of filtered out (ex post weaker) forecasters based on historical MSPE. We employ the screen that at least five forecasts over the rolling window of six months must have been made. We form Most, Between, and Least groups based on the percentage of the time that each forecaster is filtered out over the sample period, with the High group containing those filtered out most often. The sample sizes for Least, Between, and Most are 126, 123, and 130, respectively. The last column reports the difference in means and medians of the characteristics of filtered out forecasters between Most and Least with both a $t$-test and a Wilcoxon Z-test for equality. Note that ${ }^{* * *}, * *$, and * indicate significance at $1 \%, 5 \%$, and $10 \%$, respectively.

\begin{tabular}{lllccc}
$\begin{array}{l}\text { Group based on percentage of time } \\
\text { forecasters are filtered out }\end{array}$ & & Least & Between & Most & $\begin{array}{c}\text { Difference } \\
\text { (Most-Least) }\end{array}$ \\
\hline STALENESS_MEAN & Mean & 20.957 & 21.711 & 21.760 & $0.803^{* *}$ \\
& Median & 20.146 & 21.226 & 20.988 & $0.841^{* *}$ \\
CONF_INT_MEAN & Mean & 0.166 & 0.162 & 0.193 & $0.027^{* *}$ \\
& Median & 0.153 & 0.154 & 0.170 & $0.017^{* * *}$ \\
SD & Mean & 1,194 & 1,302 & 1,293 & $99^{* * *}$ \\
& Median & 1,312 & 1,349 & 1,329 & $16^{* *}$ \\
RELATIVE_IMPUTED_IND_VOL_MEAN & Mean & -0.107 & -0.104 & 0.258 & $0.365^{* * *}$ \\
& Median & -0.204 & -0.191 & 0.059 & $0.262^{* * *}$ \\
\hline
\end{tabular}




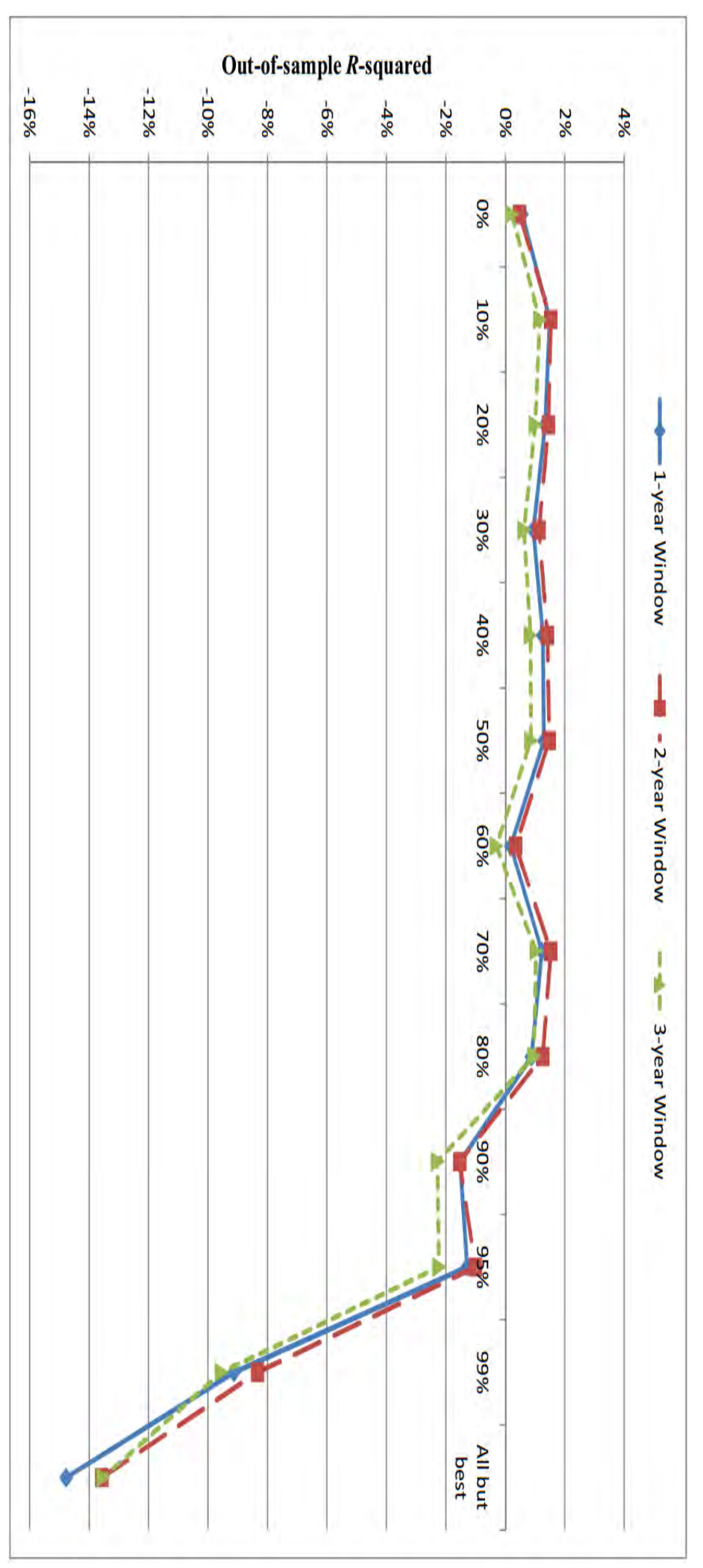

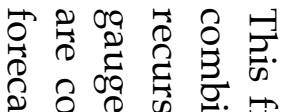

on 0 is.

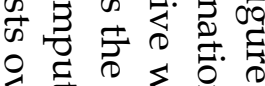

륭

\& 050

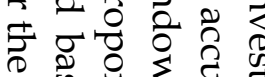

क

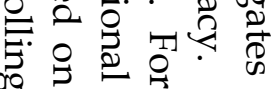

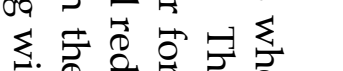

㲘

ट $>$ है क

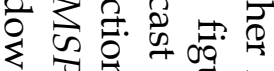

西雪.

क

ज के क्ष

ब

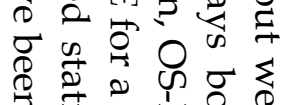

吾.

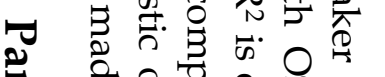

员 0 要

总. 帝

?.

क

党

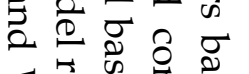

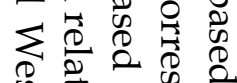

๑ 20

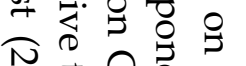

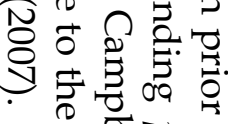

$\sum_{0} \vec{D}_{0} \cdot$

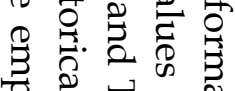

훙후융

F 80

o

\%o

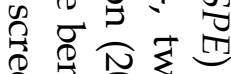

今 ह

表

क्ष

$\approx$ 궁

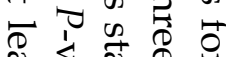

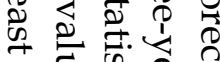

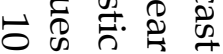




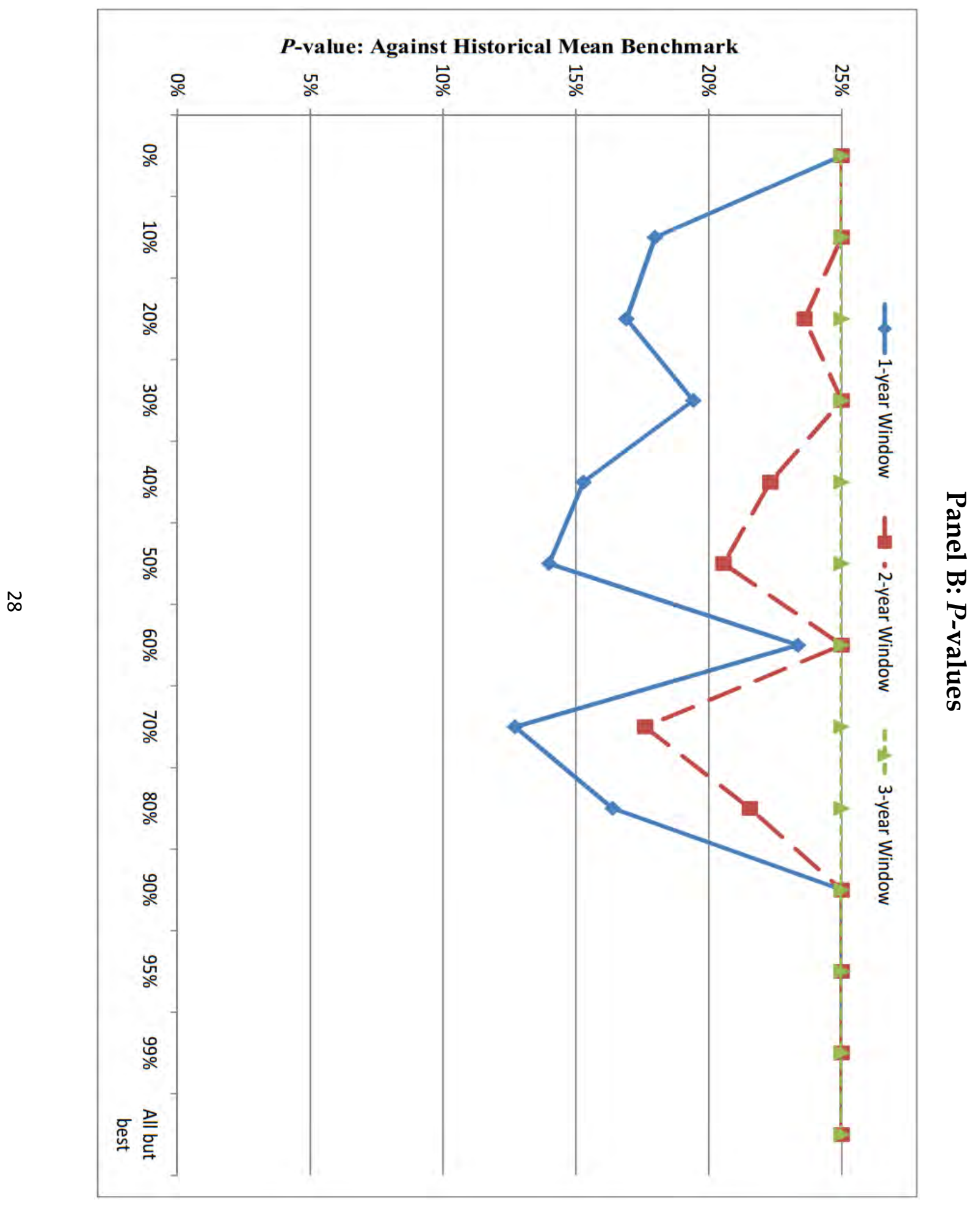




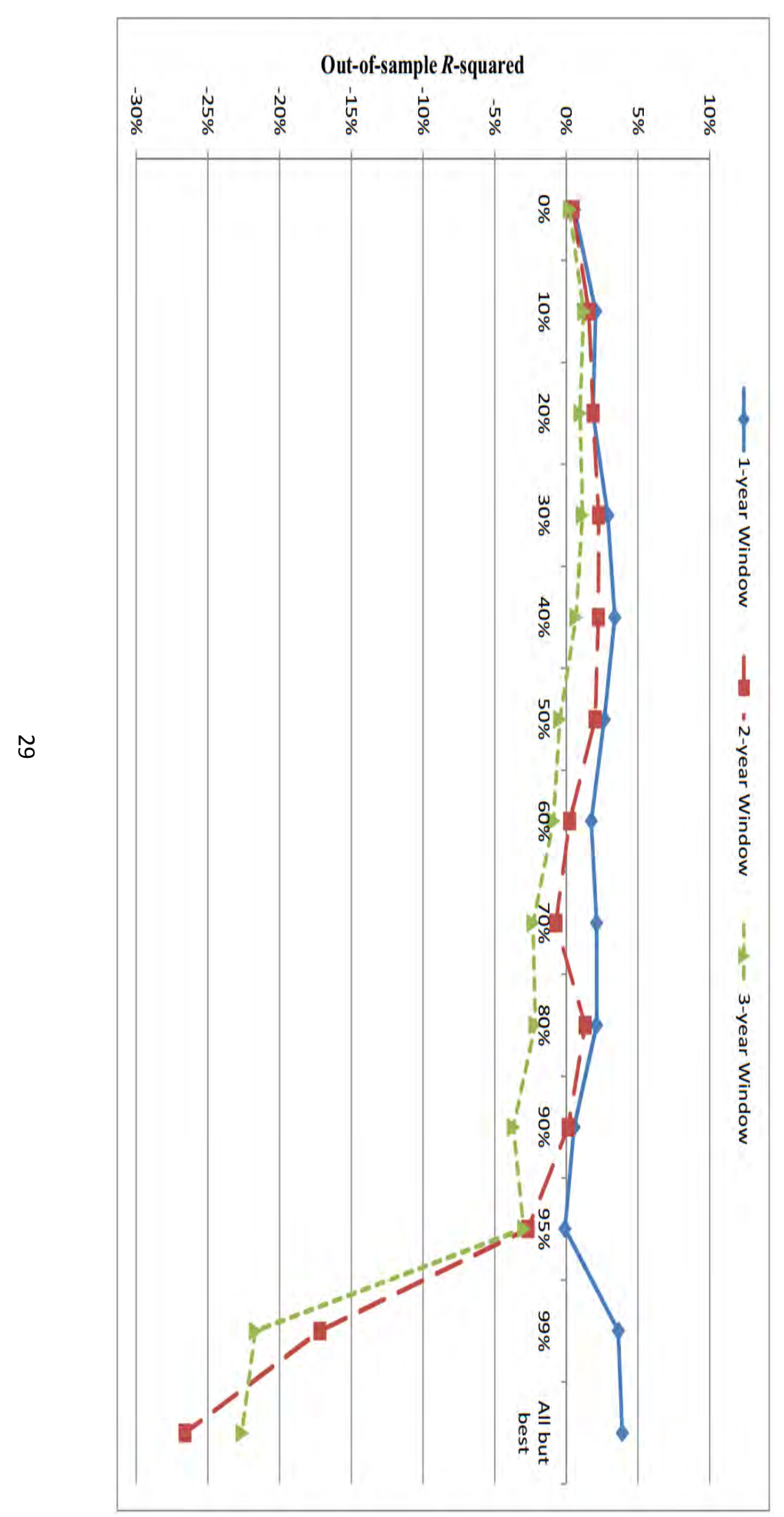

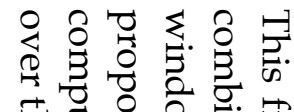

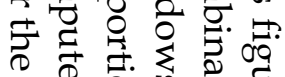

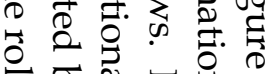

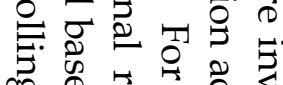

वa

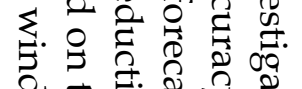

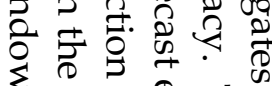

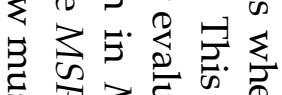

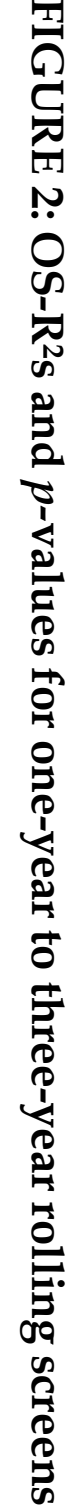

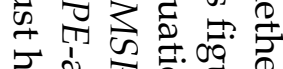

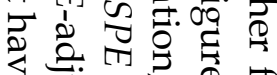

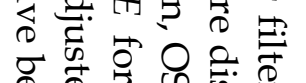

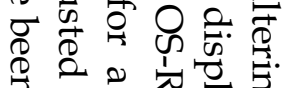

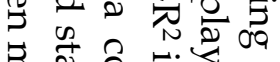

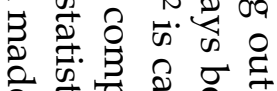

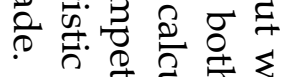

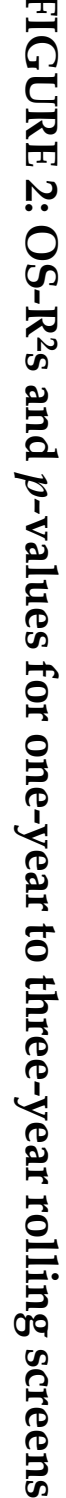

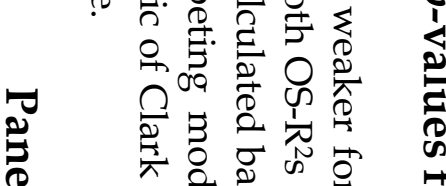

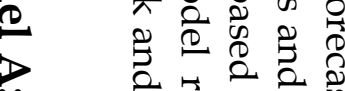

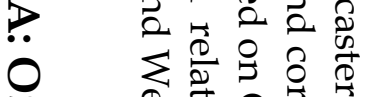

फ $\sum_{0} \%$

党

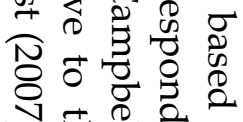

ج্ব

$\sum_{0} \vec{E}_{0} \sum_{i}^{0}$

웅

记

(4)

눈

o

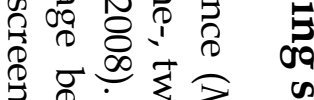

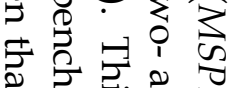

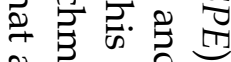

$\approx$ क

춧

क

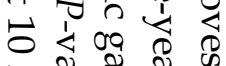

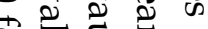

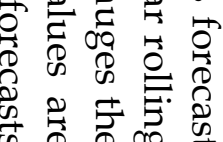

0
0
0
0
0
0
0
0
0
0
5
0
0
0
0
0
0
0
0
5
0
0
0
0
0
0
0 


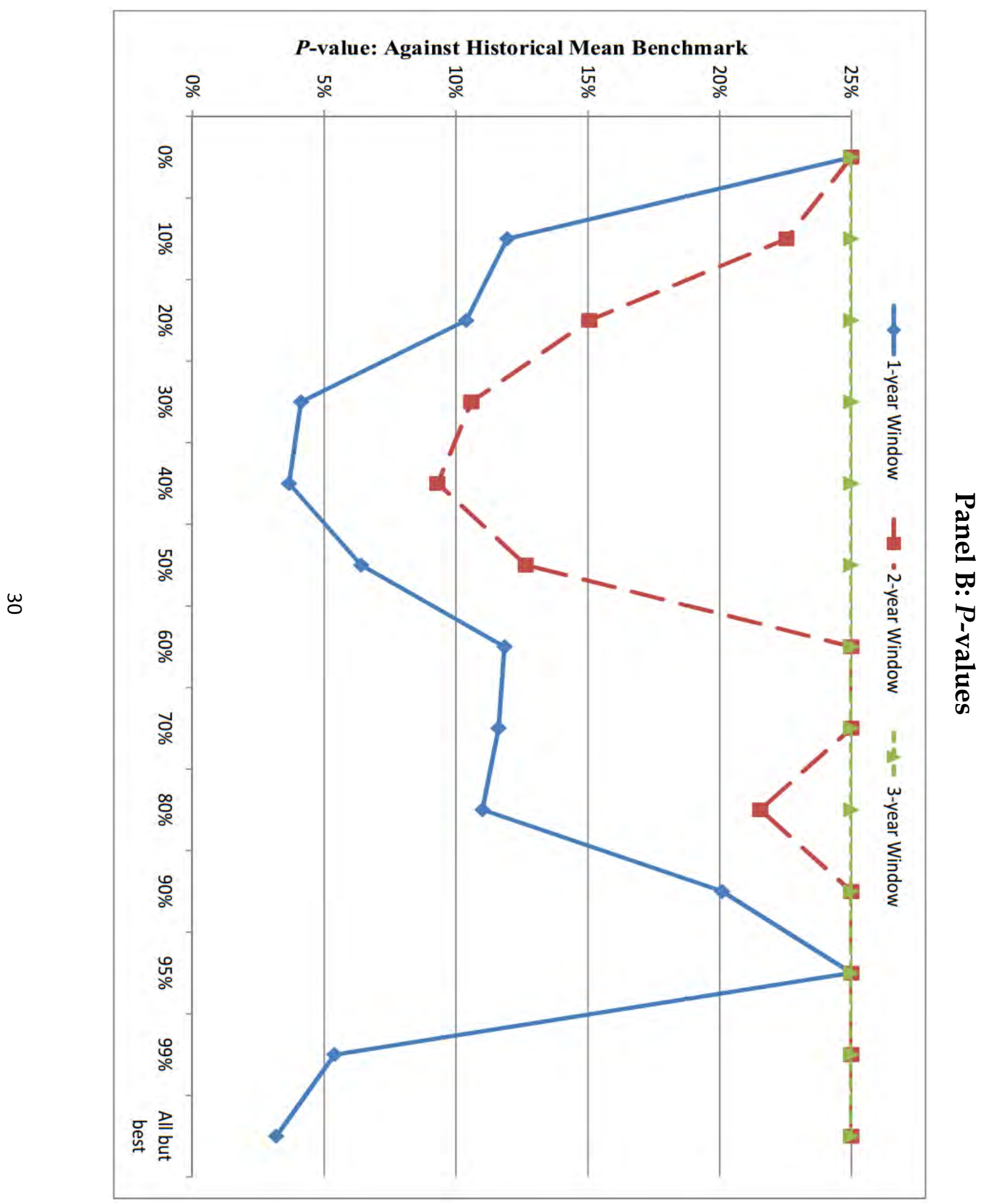




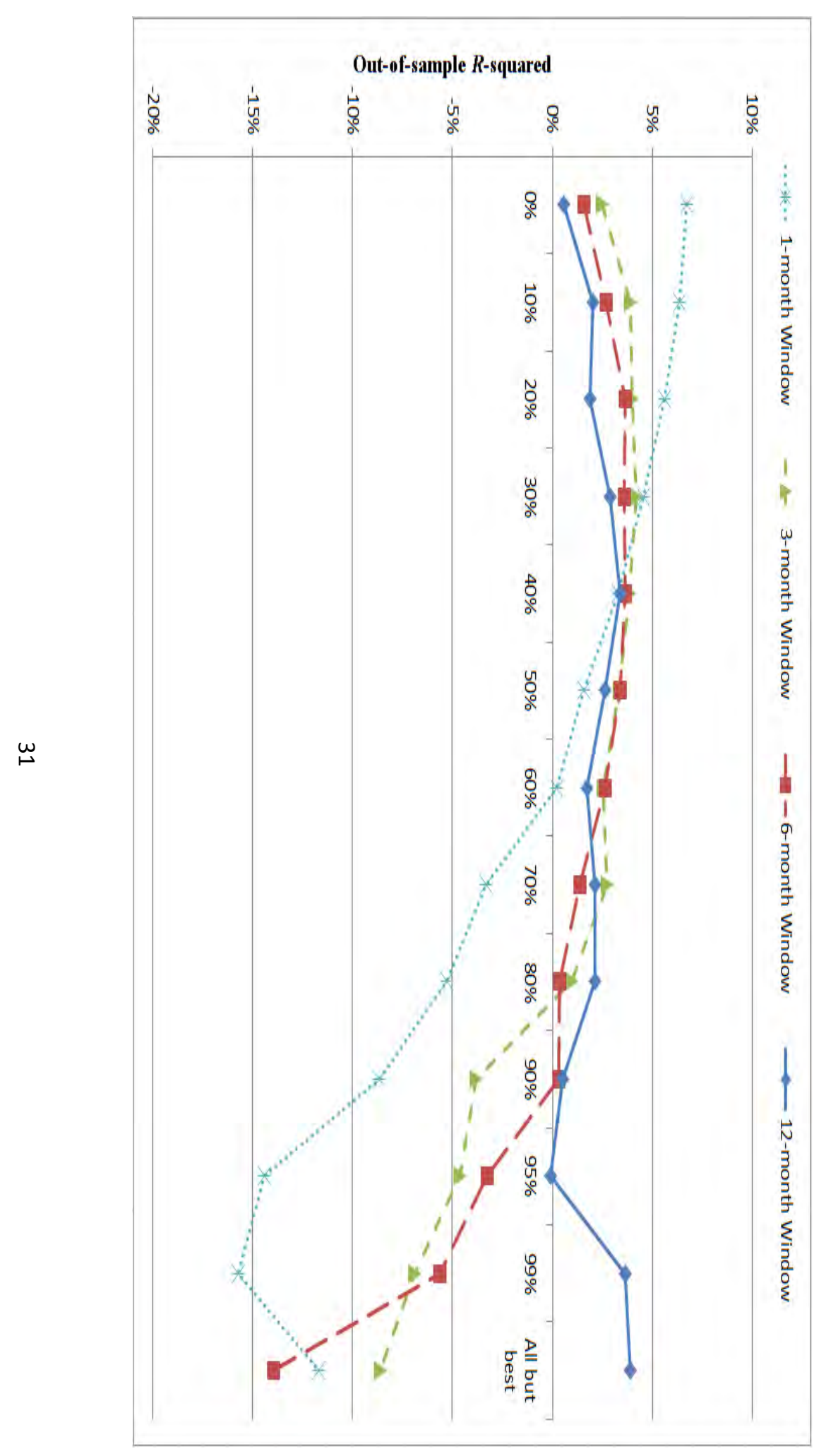

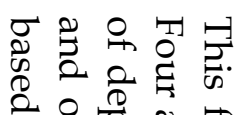

200

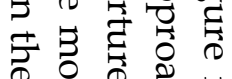

굴

क्ञ

ד彳?

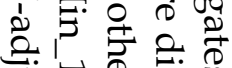

눌

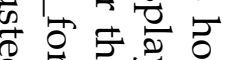

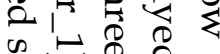

m

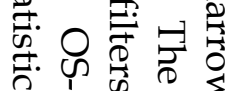

兄空贯

疍

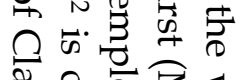

ب.

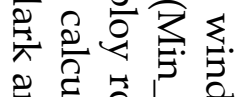

है

क

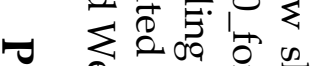

॰ क

D

$>$ ơ 0 过

$\ddot{0}) \sum_{0}$

फ $\bigcirc \circ$ 卷

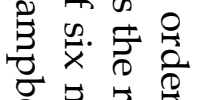

궁요

응

芑宽宫

궁유.

공

ज ज

定造

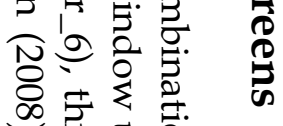

क्ञ

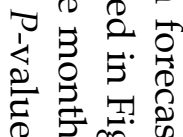

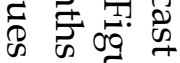

\%客家

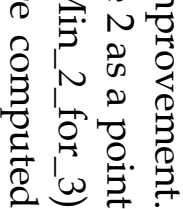




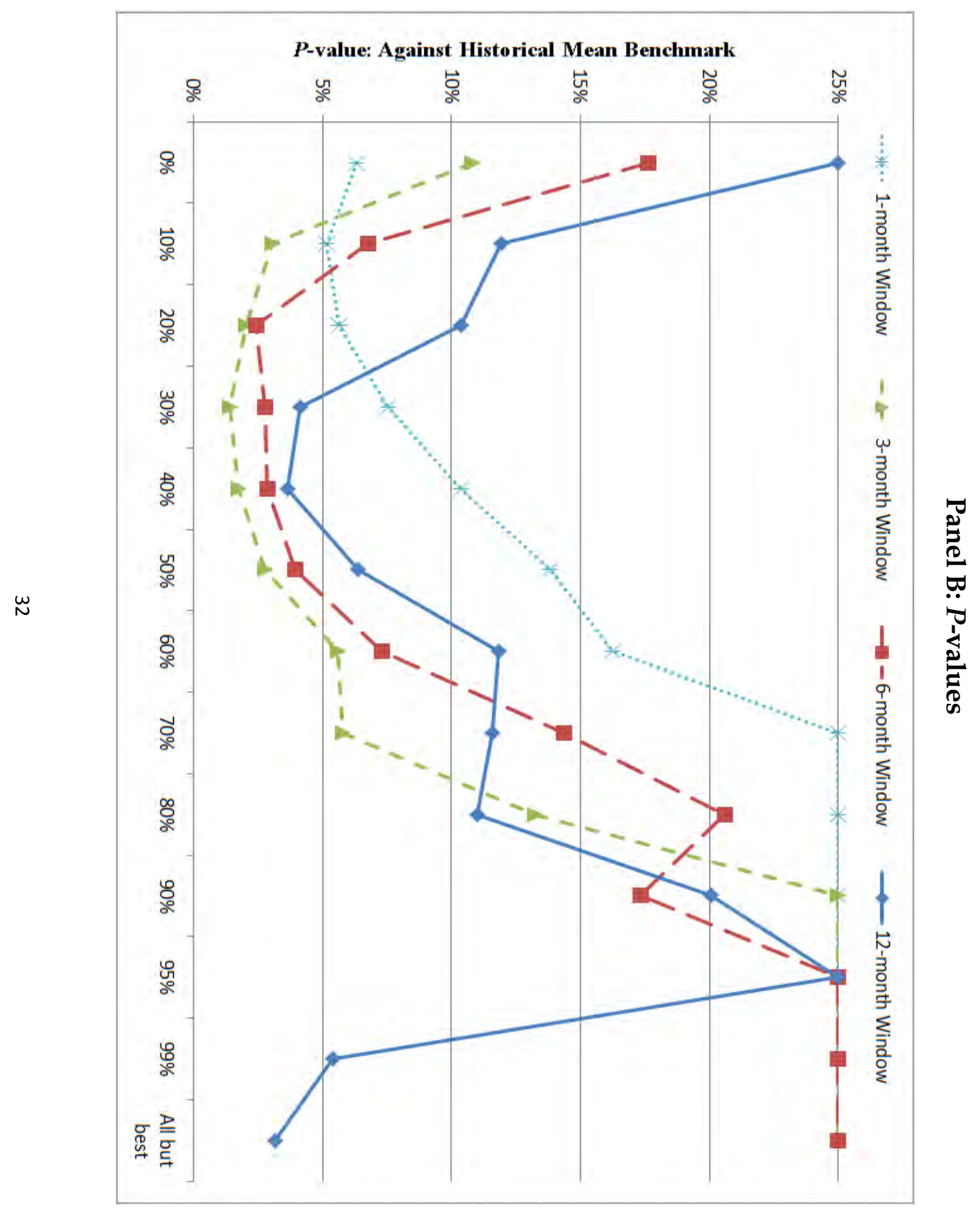



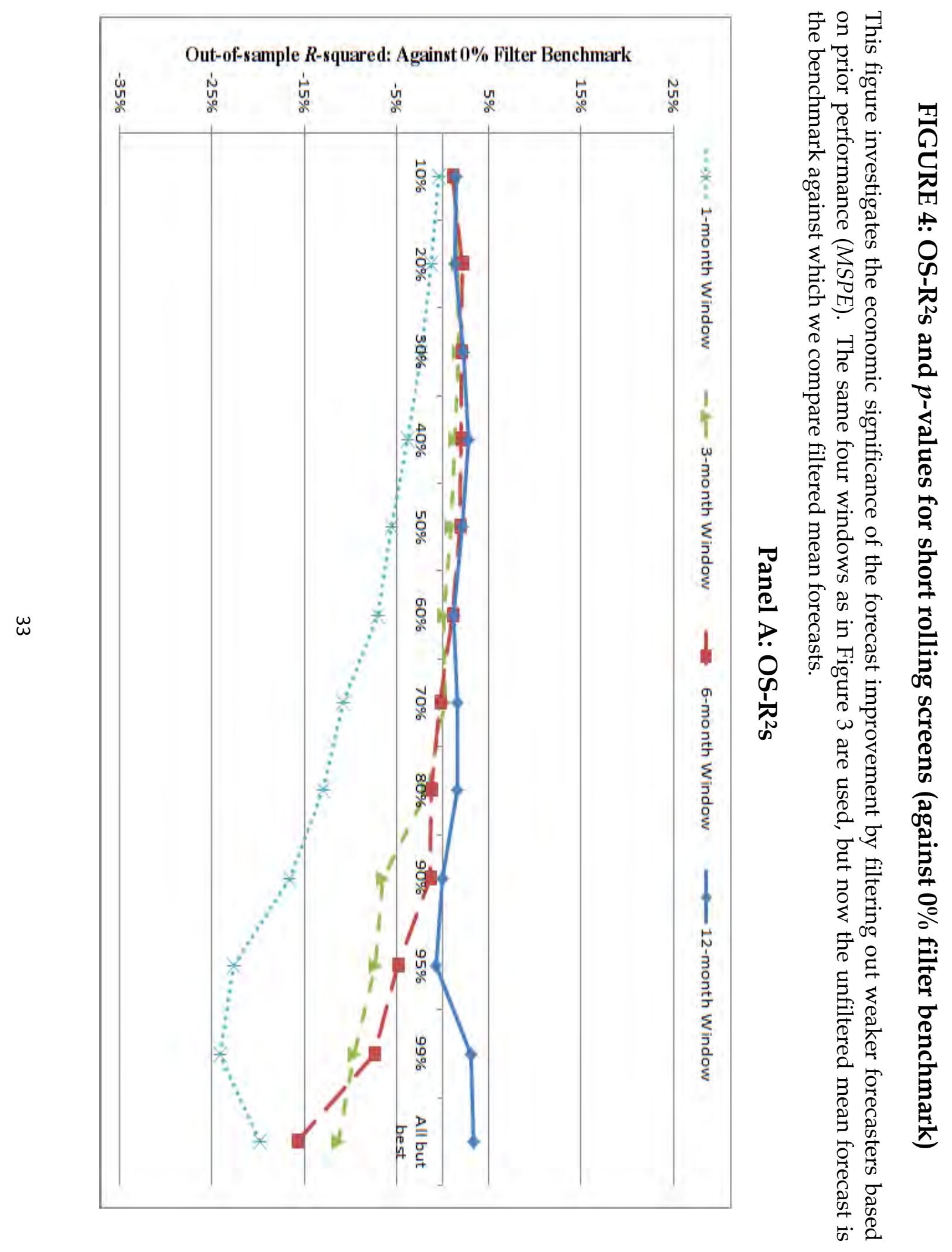


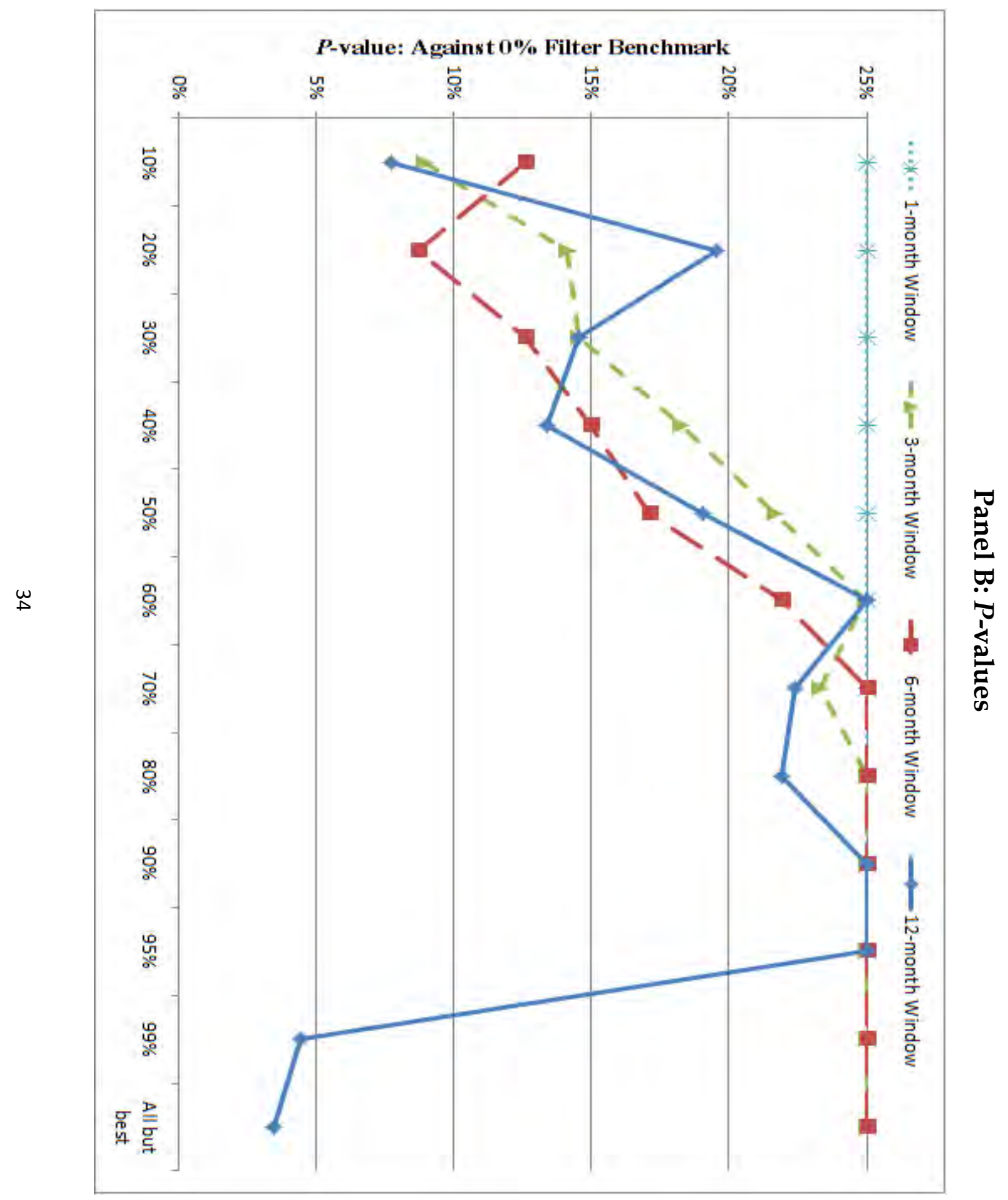




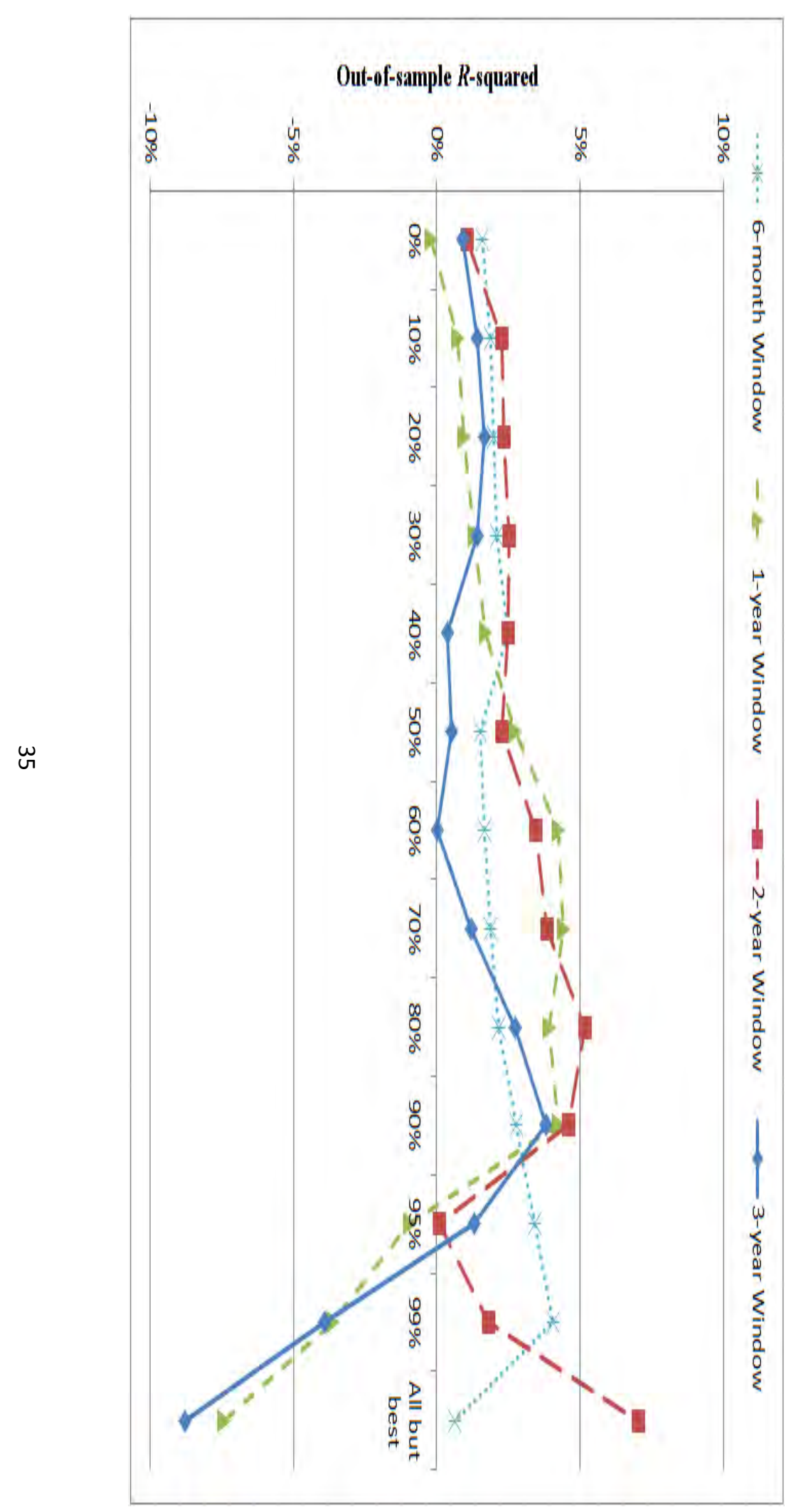

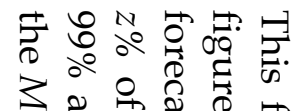
ज旅

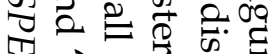
मे के क

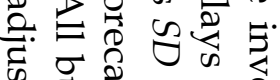
क छ 2.

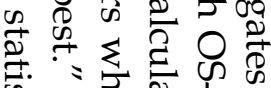
ज. =

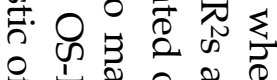
党冚虽

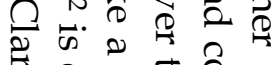
수숭요

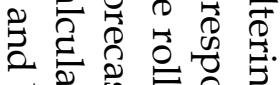
$\sum$ 要

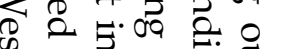
足

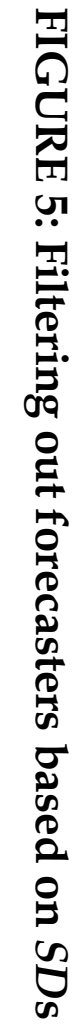
贻.

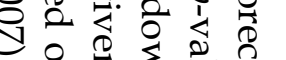
7

5
0
0
0
0
1
0
0 5 证 今 उ

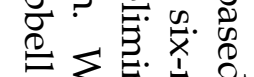
\% పे 0 \%

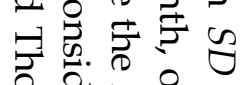
o 苟 高家范

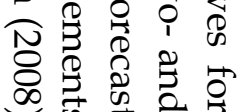
क्ष

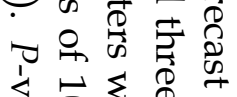
证

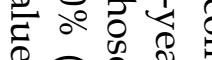

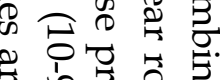

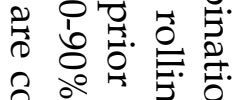
8 의

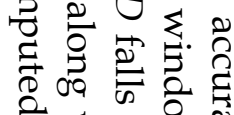

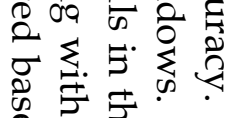

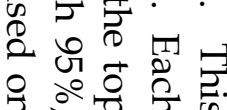




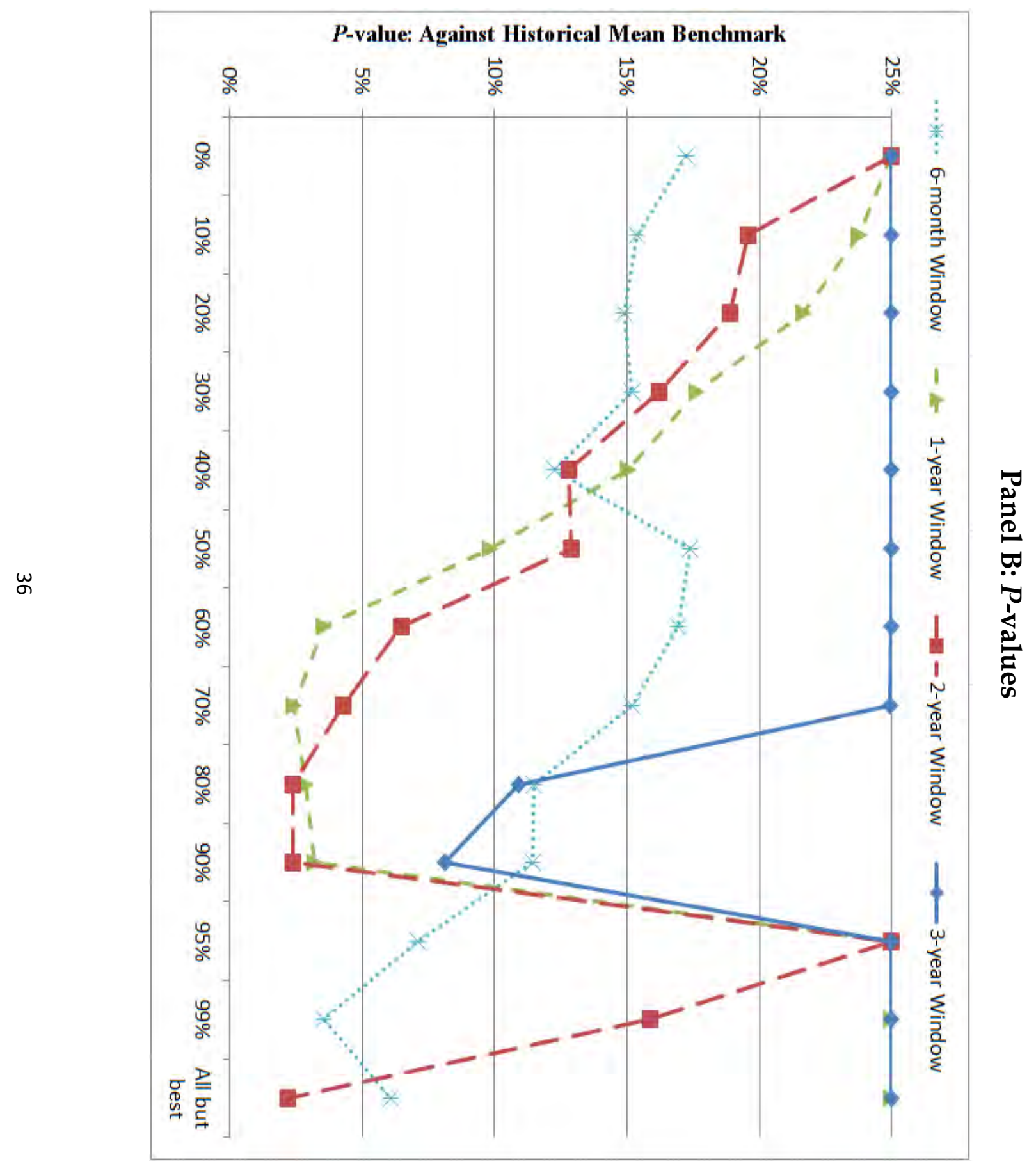

